\title{
Meta-regression analysis of the effect of lifestyle interventions on mediators of inflammation in postmenopausal breast cancer women with cardiovascular risk factors
}

Dr Jean Paul Muambngu Milambo ( $\sim$ jeanpaulmilambo2@gmail.com )

STELLENBOSCH UNIVERSITY https://orcid.org/0000-0003-0552-5378

Maritha Kotze

Stellenbosch University

Erasmus Rajiv

Stellenbosch University

John Akudugu

Stellenbosch University

Tamuzi Lukenze Jacques

Stellenbosch University

\section{Research article}

Keywords: Postmenopausal breast cancer, medically supervised exercises, markers of inflammation, cardiovascular related adverse events

Posted Date: December 16th, 2019

DOI: https://doi.org/10.21203/rs.2.18867/v1

License: (c) (1) This work is licensed under a Creative Commons Attribution 4.0 International License.

Read Full License 


\section{Abstract}

Background: Chronic inflammation is associated with obesity, dyslipidemia, and different types of malignancies that may play a complex role in the risk of breast cancer (BC) recurrence and therapy related side effects. The purpose of this review was to determine the effects of lifestyle interventions on mediators of inflammation (C-reactive protein (CRP), interleukin 6 (IL-6) and tumor necrosis factor a (TNFa)) and other therapy related adverse events in postmenopausal BCS with cardiovascular related risk factors.

Methods: A systematic search for relevant articles was performed according to the Preferred Reporting Items for Systematic Review and Meta-Analysis criteria using available databases (PubMed, Scopus, The Cochrane Library, OpenGrey, Google Scholar and CENTRAL).

Results: Twelve eligible randomized controlled trials (RCT) met the inclusion criteria. The mean ages of postmenopausal $\mathrm{BC}$ women ranged from 49 to 56 years. The meta-regression revealed that there was moderate evidence that MSE decreased the mean difference (MD) of inflammatory markers in BCS, with CVD risk factors (MD: $0.31 ; 95 \% \mathrm{Cl}: 0.05$ to $0.57, \mathrm{P}=0.02$; heterogeneity: $\mathrm{Tau}^{2}=0.12 ; \mathrm{Chi}^{2}=106.30, \mathrm{df}=$ $\left.19, I^{2}=0.50 .4 \%\right)$.

Conclusion: There is a moderate level of evidence on the effects of MSE on mediators of inflammation in postmenopausal BCS with cardiovascular risk factors. A number of shared risk factors between postmenopausal status and CVD should be considered, while treating postmenopausal BCS.

\section{Background}

Breast cancer (BC) is the most common malignancy in females worldwide. In 2012, 1.7 million new cases of $\mathrm{BC}$ were diagnosed globally, and $\mathrm{BC}$ was responsible for approximately 700,000 deaths ${ }^{1}$. BC develops over a timeframe of 2-3 decades prior to clinical manifestation, with a cumulative lifetime risk of $4.6 \%$ in women by the age of 74 years ${ }^{1}$. BC treatment have evolved rapidly, resulting in over $90 \%$ survival, making $\mathrm{BC}$ patients the largest cancer survivorship group in different countries ${ }^{2}$. Cancer and cardiovascular diseases (CVD) are two leading causes of death from non-communicable diseases (NCDs) worldwide; because of shared genetic and sporadic risk factors that affect both diseases and inflammation is identified as major unifying risk factor between these conditions ${ }^{3}$. Bardia et al., (2012) identified that postmenopausal women with BC (43\%) had a predicted 10-year CVD risk equivalent to BC recurrence risk (OR: $6.1,95 \% \mathrm{Cl}: 3.4-11.2 \%)^{4}$. Etiology of $\mathrm{BC}$ is multifactorial, with genetic, environmental, medical, and lifestyle factors interacting to produce a given malignancy ${ }^{5}$. Poor lifestyle, menopausal status, BC treatment strategies, and mutations in the BRCA1/2 genes are also associated with BC mortality and morbidity ${ }^{5}$. CVD risk factors increase cardiovascular toxicity due to anti-cancer drugs and pose a significant dilemma on treatment outcome. A review conducted by Schiavon and Smith (2014) has reported the benefits and disadvantages of tamoxifen and aromatase inhibitors (Als) in BC survivors ${ }^{6}$. However, various side effects of these therapies, such as osteoporosis, fatigue, CVD dysfunction, 
sarcopenia, hyperlipidemia, hypercholesterolemia, hypertension, immunosuppression, sleeping disturbance and inflammation, contribute in reducing health related quality of life (HRQOL) of BCS $6,7,8$. Evidence has shown that mortality rate due to CVD among BCS accounts for $35 \%$ of the non-cancerrelated deaths in those age 50 years and older, and cardiovascular mortality is the greatest single noncancer-related cause of death in retrospective cohort study ${ }^{8}$. The above statistics might raise some concerns, especially in the adjuvant setting where the aim of treatment is to cure, and for postmenopausal patients who are already at risk for CVD. BC and CVD are associated, with high level of evidence supporting inflammation as unifying risk factor of both conditions sharing the similar casual pathways. In fact, chronic inflammatory condition is associated with oxidative stress, so a number of predictors of NCD associated with inflammation and oxidative stress, such as diabetics, obesity, dyslipidemia, and different type of malignancies, may play a role in the complex effect on BC risk of recurrence and therapy related side effects ${ }^{7,9}$. Furthermore, there is an evidence-based link between BC and postmenopausal status with obesity, making the latter a consistent predictor for both conditions 9 . This is the case for hyperlipidemia, which is a known risk factor for atherosclerosis, whereas low-density lipoprotein (LDL) was suggested to be associated with development of cancer subtypes including BC ${ }^{9}$. Lewis et al., (2017) found that BRCA1 and BRCA2 gene mutations may contribute in preservation of cardiovascular system function, and these gene abnormalities are associated with elevated risk of CVD in $\mathrm{BC}$ patients receiving anthracycline-based therapy ${ }^{10}$. Moreover, Lonning et al., (2014) reported that higher levels of estrogen in overweight and obese postmenopausal BC patients before and during Als might be due to body mass index (BMI) effects on estrogen metabolism ${ }^{11}$. High $\mathrm{BMI}$ is associated with poor clinical outcome and treatment failure in BC patients. Both overweight (BMI $\geq 25 \mathrm{~kg} / \mathrm{m}^{2}$ ) and obese (BMI $\geq 30 \mathrm{~kg} / \mathrm{m}^{2}$ ) postmenopausal BC patients are at increased risk of treatment side effects, mortality and morbidity ${ }^{12}$. The evidence provided by Passos et al., (2017) on the effects of physical activity on excess adipose tissue and cancer risk reduction revealed that sedentary lifestyles, unhealthy diet, and overweight are established risk factors that play a role with other risk behaviors, which increase the risk of developing cancer subtypes, type 2 diabetes and CVD, and reduce HRQOL of susceptible patients ${ }^{13}$. This review also emphasized the benefits of physical activity on NCDs prevention, and incorporation of exercise programs in adjuvant therapy for health promotion. This is because the common biological pathways of metabolic syndrome due to imbalances in pro-inflammatory and anti-inflammatory markers connected to adipose tissues are positively associated with risk of NCDs. Reviewing the literature, studies have reported the role of physical activities in inflammatory profiles in BCS on adjuvant therapies ${ }^{14-16}$. A number of pleiotropic cytokines are associated with cancer subtypes and chronic inflammation correlated with sedentary lifestyles, obesity, and lack of physical activity ${ }^{13}$. Interleukin-6 (IL-6) and tumor necrosis factor alpha (TNF-a) are inflammatory markers generated by different cells, including carcinogenic cells, infiltrating macrophages and adipocytes which can contribute to inflammation ${ }^{17}$. The authors also found that C-reactive protein (CRP) and TNF-alpha maybe elevated in breast tissues and other cancer subtypes. IL- 6 has been found associated with metastasis development and BC recurrence ${ }^{17,18}$. Additionally, IL- 6 is a known risk factor for CVD and metabolic syndrome, as well as associated with overweight and advanced age. High concentrations of CRP are associated with increased mortality and morbidity among 
postmenopausal BCS ${ }^{19}$. Moreover, Khan et al., (2013) confirmed the association between markers of obesity (BMI, waist circumference and percentage of body fat) and inflammatory profiling ${ }^{17}$. Elevated biomarkers may cause homeostatic problems in systemic and local tissues in women with postmenopausal BC, by increasing transcription of the human aromatase (cytochrome CYP19A1) gene encoding the aromatase enzyme ${ }^{20}$. Obesity is associated with an increased body aromatization and may be an indirect cause of insufficient estradiol depletion. It is important to apply personalized patients approaches to differentiate patients likely to benefit from lifestyle interventional strategies and/or surgical risk reduction measures based on evidence based on pooled evidence from robust metaregression. These strategies may help to minimize the incidence rate of cardiac toxicity and additional side effects that reduce BCS adherence on endocrine therapy ${ }^{21}$. Current clinical practice of exercises recommended by American Cancer Society (ACS) ${ }^{22}$ and American College of Sports Medicine (ACSM) ${ }^{23}$, suggests that aerobic/stretching exercises of $150 \mathrm{~min} /$ week of moderate-intensity or $75 \mathrm{~min} /$ week of vigorous-intensity, or an equivalent combination should be initiated for each cancer survivors upon physician fitness examination ${ }^{24}$. Tailored exercise programs have been proven effective in decreasing pro-inflammatory markers in BCS ${ }^{24}$. These may include TNFa, insulin-like growth factor 1 (IGF-1), adiponectin, IL-6, toll-like receptor 4, cyclooxygenase-2, IL-1 and CRP, independent of gender, age, BMI, and blood glucose status ${ }^{25,26}$. Increased levels of these markers have been associated with treatment nonresponse in $\mathrm{BC}$ treatment strategies. The association between elevated inflammatory markers and $\mathrm{BC}$ risk, specifically with increased markers such as CRP and IL-6 was reported ${ }^{27-29}$. Not all reviews have found a statistically significant association between exercises as a lifestyle measure and BC risk, especially among postmenopausal patients on endocrine therapy. The exercises were recommended to reduce treatment related side effects by improving HRQOL in cancer survivors, based on the current published studies ${ }^{30-35}$. Mills et al., (2017) evaluated the effect of exercises on markers of inflammation in BCS; the summary of the finding revealed that exercise might help to improve the concentration of mediators of inflammation ${ }^{18}$. However, multiple limitations in the current literature regarding the effect of exercise on inflammatory markers were noted. Types of exercises, lack of exercise regimens for cancers subtypes, doses and intensities vary across studies. Meta-analysis was not performed to assess the level of evidence and risk of bias recommended for reporting systematic reviews, and all these resulted in nongeneralizability of the review results ${ }^{14,18}$. Furthermore, a meta-regression with high quality of RCTs should also explore the correlation between ACSM and ACS exercise regimens in assessing the doseresponse relationship between different types of MSE programs and survival outcomes stratified by BC subtypes. Although the robust review on the effects of exercises in cancer survivors shows the benefit of physical activity in improving HRQOL, the evidence is not sufficient to recommend exercises for different cancer subtypes. The authors suggested that a pre-screening evaluation should be performed to assess the effects of disease, treatments, and comorbidities for personalized exercise regimens ${ }^{34}$. A review by Lof et al., (2012) on the effects of exercises on inflammatory markers in BCS did not find statistically significant link between IL- 6 and exercise program ${ }^{36}$. Only a single trial suggested that exercises may decrease CRP level among BCS, and meta-analysis was not undertaken because of heterogeneity of the studies included in the review ${ }^{36}$. A recent review performed by Meneses-echávez et al. (2015) on the 
effect of exercise on mediators of inflammation in BCS revealed that exercises improved IL- 6 concentration, but no significant changes were found in serum concentrations of CRP ${ }^{37}$. Further, metaregression with a rigorous methodology is needed to resolve discrepancies in results. To the best of our knowledge, no meta-regression of RCTs have yet been conducted to assess the effects of MSE on the shared inflammatory markers in postmenopausal BCS survivors at risk for CVD. Therefore, the purpose of this review was to determine the effects of lifestyle interventions on mediators of inflammation in postmenopausal BCS with CVD risk factors and other therapy related adverse events, including combining of data with meta-analysis, if applicable. Evidence of this nature could provide treatment options to decrease risk of not only BC recurrence and mortality, but also risk of CVD in postmenopausal BCS on adjuvant therapy.

\section{Methods}

Preferred Reporting Items for Systematic Reviews and Meta-Analyses (PRISMA) statement is the approach used to combine the relevant studies as described in the literature ${ }^{38}$. Review protocol was registered on the PROSPERO (CRD42017079864) https://www.crd.york.ac.uk/PROSPERO.

\section{Ethics considerations}

The first author of this review verified and confirmed that all included studies were approved by the respective Ethics Committees.

\section{Search strategy}

Two authors independently screened the search findings. The reviewers were blinded to both the name of primary study authors and to the results of the potential studies. Comprehensive searches were performed from March 2018 to December 2018 in PubMed, Embase, Scopus, and Cochrane Central Register of Controlled Trials (CENTRAL), using Boolean operators based on Population(P), Intervention( $(I)$, Comparator $(\mathrm{C})$, outcome $(\mathrm{O})$ framework below for identification of the records based on the following MeSH terms: (" medically supervised exercises"[MeSH Terms] OR "exercise"[All Fields] OR "exercises"[All Fields] OR "exercise therapy"[MeSH Terms] OR ("exercise"[All Fields] AND "therapy"[All Fields]) OR "exercise therapy"[All Fields]) AND (inflammatory[All Fields] AND ("Markers"[Journal] OR "markers"[All Fields]) AND postmenopausal[All Fields] AND ("breast neoplasms"[MeSH Terms] OR ("breast"[All Fields] AND "neoplasms"[All Fields]) OR "breast neoplasms"[All Fields] OR ("breast"[All Fields] AND "cancer"[All Fields]) OR "breast cancer"[All Fields])). In addition, the medical terms such as (carcinoma, breast cancer, tumor), lifestyle interventions (exercise programs, diet, physical activity, or supervised exercise programs), and outcomes (inflammation, mediators, CVD risk factors, anti-inflammatory, cytokines, interleukin IL6, CRP, tumor necrosis factor or TNF alpha) were added to secondary search strategies. Studies published between 2000 and 2018 were considered in this review. Two authors independently screened the studies 
for eligibility. Disagreement was resolved by consensus and, where necessary, arbitration by third reviewer.

\section{Inclusion criteria}

The trials were included in this study, if they met the following criteria:

- Randomized controlled trials (RCTs) involving postmenopausal BCS survivors with or without CVD risk factors;

- Included experimental group performing MSE programs (categorized as resistance, aerobic, combined aerobic and stretching exercises or other recommend by ACS or ACSM);

- Included a comparator group following a specified period of time, undertaking conventional care or usual care, education without intervention;

- Specified biomedical techniques used to measure serum concentrations of at least one of the following inflammatory markers: cytokines (IL6, TNF-a, and CRP).

MSE programs were defined as any body movement causing an increase in energy expenditure and involving a structured individualized regimen by assistance of a sport physician or physiotherapist. This MSE should be performed in a systematic manner in terms of intensity, frequency, doses, duration, measurement of HR for CVD risk in patients with BC, calculated 1-RM (if possible) and adherence booklet provided to all subjects included in intervention group.

\section{Exclusion criteria}

Studies were excluded if the MSE was combined with diet intervention, mechanical therapy, premenopausal status, observational studies, quasi-experimental studies, psychosocial therapeutic strategies, lack of pre and post data regardless of various attempts made to contact the primary study authors for clarification, if necessary.

\section{Study outcomes}

The outcomes assessments were serum levels of inflammatory markers (IL-6, CRP and TNF-alpha) following MSE programs. The techniques used to measure the above named markers, such as ELISA kits or cytokine immunoassays.

\section{Data extraction}

Data were extracted independently by two authors blinded to the name of primary study authors. The indicators of extraction form includes: 
- Study designs, authors, year of publication, type of randomization if applicable, mean age of study participants, stratified sample size per group allocations, current BC treatment if reported (radiation, surgery, chemotherapy, hormonal therapy, comorbidities if reported, BC staging and baseline information about the outcomes measures;

Data related to intervention under investigation included:

- MSE modality, length, frequency (sessions/week), duration of training (minutes/session), and intensity of training (maximal heart rate \%);

Data related to outcomes measures included:

- Baseline serum levels of markers of inflammation and adverse events reported during the follow-up and endpoint of the study, if reported.

After data extraction, we assessed for completeness and accuracy by a third author. Discrepancies were resolved via the corresponding authors of the initial RCTs.

\section{Quality assessment and personal study quality}

Two authors independently assessed the quality of eligible nine RCTs (Table 1). Risk of bias was conducted using the Cochrane risk of bias tool for the appraisal of RCTs, as outlined in the Cochrane Handbook for Systematic Reviews of Interventions version 5.1.0 ${ }^{39}$. The tool contains six domains and each domain was assigned a judgement related to the risk of bias. The judgement could be 'low risk', 'high risk', or 'unclear risk'. The latter judgement was assigned, if the risk of bias of a characteristic in an included study was judged to be unclear, or if there was insufficient information on which to base the judgement. We compared excel datasets between two data extractors and the third author was consulted to resolve discrepancies. We reported the summary of the risk of bias in Table 2. Figure 1 shows the flow diagram of the included studies. All analyses were performed, using Review Manager Software ${ }^{39}$. 
Table 1

Characteristics of studies included in meta-analysis

\begin{tabular}{|c|c|c|c|c|}
\hline \multirow[t]{2}{*}{ Authors } & \multicolumn{2}{|c|}{$\operatorname{Age}(\mu / S D) /$ sample$(N)$} & \multirow{2}{*}{$\begin{array}{l}\text { Types } \\
\text { exercises }\end{array}$} & \multirow[t]{2}{*}{ Outcomes } \\
\hline & MSE & Control & & \\
\hline $\begin{array}{l}\text { Schmidt, et al.,(2016) } \\
\text { [40] }\end{array}$ & $\begin{array}{l}57.1 / 8.9 \\
N=54\end{array}$ & $\begin{array}{l}57.3 / 8.8 \mathrm{~N} \\
=49\end{array}$ & $\begin{array}{l}\text { SE;A,5d/wk, } \\
52 \text { wk, HR: } 7-8 / 10\end{array}$ & IL-6 \\
\hline $\begin{array}{l}\text { Fairey, et al., ( 2005). } \\
\text { [41] }\end{array}$ & $\begin{array}{l}57.1 / 8.9 \\
N=24\end{array}$ & $\begin{array}{l}57.3 / 8.8 \\
N=28\end{array}$ & $\begin{array}{l}\text { SE, cycle ergometers } \\
\text { 3x/wk,15wk; } \\
\text { HR: } 7-7,5 / 10\end{array}$ & CRP \\
\hline $\begin{array}{l}\text { Van Vulpen et al., } \\
\text { (2018) [24], } \\
\text { German }\end{array}$ & $\begin{array}{l}50.8 / 9.1 \\
N=64\end{array}$ & $\begin{array}{l}52.3 / 9.3 \\
N=66\end{array}$ & $\mathrm{SE}, \mathrm{AR}, 60 \mathrm{~min} / \mathrm{d}, 18 \mathrm{wk}, \mathrm{ACSM}$ & IL-6 \\
\hline \multirow{3}{*}{$\begin{array}{l}\text { Bower et al. (2014); [42] } \\
\text { USA }\end{array}$} & \multirow{3}{*}{$\begin{array}{l}54 / 6 \\
N=15\end{array}$} & \multirow{3}{*}{$\begin{array}{l}53 / 5 \\
N=13\end{array}$} & \multirow[t]{3}{*}{$\mathrm{SE}$, Yoga $(90 \mathrm{~min} / 2 / \mathrm{wk} / 12 \mathrm{wk}$} & IL6 \\
\hline & & & & CRP \\
\hline & & & & TNF a \\
\hline \multirow{2}{*}{$\begin{array}{l}\text { Ergun et al., (2013), [43] } \\
\text { Turkey }\end{array}$} & \multirow{2}{*}{$\begin{array}{l}50 / 8 \\
N=30\end{array}$} & \multirow{2}{*}{$\begin{array}{l}55 / 7 \\
N=30\end{array}$} & \multirow{2}{*}{$\begin{array}{l}\text { SE, AR, (45 min 3/wk, } 12 w k) \text {; } \\
\text { ACSM }\end{array}$} & IL6 \\
\hline & & & & TNF a \\
\hline \multirow{2}{*}{$\begin{array}{l}\text { Gomez et al. (2011) } \\
\text { [44] } \\
\text { USA }\end{array}$} & \multirow{2}{*}{$\begin{array}{l}50 / 6 \\
N=10\end{array}$} & \multirow{2}{*}{$\begin{array}{l}49 / 6 \\
N=10\end{array}$} & \multirow{2}{*}{$\begin{array}{l}\text { SE, AR, (90 min 3/wk/ } 8 \text { wk); } \\
\text { ACSM }\end{array}$} & IL6 \\
\hline & & & & TNF-a \\
\hline $\begin{array}{l}\text { Hutnick et al. (2005), } \\
\text { [45] }\end{array}$ & $\begin{array}{l}49 / 11 \\
N=28\end{array}$ & $\begin{array}{l}52 / 9 \\
N=21\end{array}$ & $\begin{array}{l}\text { SE; }(40-90 \mathrm{~min}, 3 / \mathrm{wk} / 24 \mathrm{wk}) \\
\text { ACSM }\end{array}$ & IL6 \\
\hline $\begin{array}{l}\text { Janelsins et al. (2011) } \\
\text { [46] } \\
\text { USA }\end{array}$ & $\begin{array}{l}56 / 10 \\
N=37\end{array}$ & $\begin{array}{l}55 / 8 \\
N=38\end{array}$ & $\begin{array}{l}\text { S, Tai Chi ( } 60 \text { min _ } 3 / w_{-} 12 \\
\text { wk) }\end{array}$ & IL6 \\
\hline \multirow{3}{*}{$\begin{array}{l}\text { Jones et al. (2013) [16] } \\
\text { USA }\end{array}$} & \multirow{3}{*}{$\begin{array}{l}56 / 10 \\
N=36\end{array}$} & \multirow{3}{*}{$\begin{array}{l}55 / 8 \\
N=31\end{array}$} & \multirow[t]{3}{*}{ SE, A(150 min3/wk _ 24 wk) } & IL6 \\
\hline & & & & CRP \\
\hline & & & & TNF a \\
\hline \multirow{2}{*}{$\begin{array}{l}\text { Rogers et } \\
\text { al. (2013)[15] }\end{array}$} & \multirow{2}{*}{$\begin{array}{l}58 / 6 \\
N=15\end{array}$} & \multirow{2}{*}{$\begin{array}{l}54 / 14 \\
N=13\end{array}$} & \multirow[t]{2}{*}{$\mathrm{SE}, \mathrm{AR}\left(\left(150 \mathrm{~min} / \mathrm{wk} \_12 \mathrm{wk}\right)\right.$} & IL6 \\
\hline & & & & TNF a \\
\hline \multirow{3}{*}{$\begin{array}{l}\text { Tizdast et al.,(2016). } \\
\text { [47] } \\
\text { Iran, }\end{array}$} & \multirow{3}{*}{$\begin{array}{l}44.1 / 4.6 \\
\mathrm{~N}= \\
44\end{array}$} & \multirow{3}{*}{$\begin{array}{l}44.1 / 4.6 \\
N=24\end{array}$} & \multirow[t]{3}{*}{ ACSM:AR; $8 w k, 3 x / w k$} & IL6 \\
\hline & & & & CRP \\
\hline & & & & TNF a \\
\hline $\begin{array}{l}\text { Swisher et al.,(2015) } \\
\text { [48] }\end{array}$ & $\begin{array}{l}53.8(43- \\
65)\end{array}$ & $\begin{array}{l}53.6(36- \\
71)\end{array}$ & SE,R, wk/12wks, $60-75 \%$ HR & II-6 \\
\hline
\end{tabular}




\begin{tabular}{|c|c|c|}
\hline Authors & 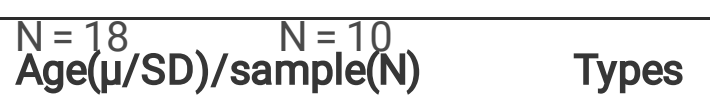 & Outcomes \\
\hline & & CRP \\
\hline & & TNF a \\
\hline
\end{tabular}


Table 2

GRADE recommendation scores.

\begin{tabular}{|c|c|c|c|c|c|c|}
\hline \multicolumn{7}{|c|}{$\begin{array}{l}\text { Patient or population: patients with } \\
\text { Settings: } \\
\text { Intervention: Inflammatory markers }\end{array}$} \\
\hline \multirow[t]{3}{*}{ Outcomes } & \multicolumn{2}{|c|}{$\begin{array}{l}\text { Illustrative comparative } \\
\text { risks* }(95 \% \mathrm{Cl})\end{array}$} & \multirow{2}{*}{$\begin{array}{l}\text { Relative } \\
\text { effect } \\
(95 \% \\
\text { Cl) }\end{array}$} & \multirow{2}{*}{$\begin{array}{l}\text { No of } \\
\text { Participants } \\
\text { (studies) }\end{array}$} & \multirow{2}{*}{$\begin{array}{l}\text { Quality of } \\
\text { the } \\
\text { evidence } \\
\text { (GRADE) }\end{array}$} & \multirow[t]{2}{*}{ Comments } \\
\hline & $\begin{array}{l}\text { Assumed } \\
\text { risk }\end{array}$ & $\begin{array}{l}\text { Corresponding } \\
\text { risk }\end{array}$ & & & & \\
\hline & Control & $\begin{array}{l}\text { Inflammatory } \\
\text { markers }\end{array}$ & & & & \\
\hline \multicolumn{2}{|l|}{$\begin{array}{l}\text { Inflammatory } \\
\text { markers }\end{array}$} & $\begin{array}{l}\text { The mean } \\
\text { inflammatory } \\
\text { markers in the } \\
\text { intervention } \\
\text { groups was } \\
0.31 \text { higher } \\
\text { (0.05 to } 0.57 \\
\text { higher) }\end{array}$ & & $\begin{array}{l}1197 \\
\text { (12 studies) }\end{array}$ & $\begin{array}{l}\oplus \oplus \oplus \Theta \\
\text { moderate }^{1}\end{array}$ & \\
\hline \multicolumn{2}{|l|}{$\begin{array}{l}\text { Inflammatory } \\
\text { markers - II-6 }\end{array}$} & $\begin{array}{l}\text { The mean } \\
\text { inflammatory } \\
\text { markers - il- } 6 \text { in } \\
\text { the intervention } \\
\text { groups was } \\
0.02 \text { higher } \\
\text { (0.05 lower to } \\
0.09 \text { higher) }\end{array}$ & & $\begin{array}{l}655 \\
\text { (12 studies) }\end{array}$ & $\begin{array}{l}\oplus \oplus \Theta \Theta \\
\text { low }^{2,3}\end{array}$ & \\
\hline \multicolumn{2}{|l|}{$\begin{array}{l}\text { Inflammatory } \\
\text { markers - } \\
\text { CRP }\end{array}$} & $\begin{array}{l}\text { The mean } \\
\text { inflammatory } \\
\text { markers - crp in } \\
\text { the intervention } \\
\text { groups was } \\
1.97 \text { higher } \\
\text { (0.25 lower to } \\
4.19 \text { higher) }\end{array}$ & & $\begin{array}{l}271 \\
\text { (6 studies) }\end{array}$ & $\begin{array}{l}\oplus \Theta \Theta \Theta \\
\text { very } \\
\text { low }^{4,5,6}\end{array}$ & \\
\hline \multicolumn{2}{|l|}{$\begin{array}{l}\text { Inflammatory } \\
\text { markers - } \\
\text { TNF-alpha }\end{array}$} & $\begin{array}{l}\text { The mean } \\
\text { inflammatory } \\
\text { markers - tnf- } \\
\text { alpha in the } \\
\text { intervention } \\
\text { groups was } \\
0.54 \text { higher } \\
\text { (0.45 lower to } \\
1.53 \text { higher) }\end{array}$ & & $\begin{array}{l}271 \\
\text { (6 studies) }\end{array}$ & $\begin{array}{l}\oplus \oplus \Theta \Theta \\
\operatorname{low}^{7,8}\end{array}$ & \\
\hline \multicolumn{7}{|c|}{$\begin{array}{l}\text { *The basis for the assumed risk (e.g. the median control group risk across studies) is provided in } \\
\text { footnotes. The corresponding risk (and its } 95 \% \text { confidence interval) is based on the assumed risk in } \\
\text { the comparison group and the relative effect of the intervention (and its } 95 \% \mathrm{Cl} \text { ). } \\
\text { Cl: Confidence interval; }\end{array}$} \\
\hline
\end{tabular}


High quality: Further research is very unlikely to change our confidence in the estimate of effect. Moderate quality: Further research is likely to have an important impact on our confidence in the estimate of effect and may change the estimate.

Low quality: Further research is very likely to have an important impact on our confidence in the estimate of effect and is likely to change the estimate.

Very low quality: We are very uncertain about the estimate.

${ }^{1}$ Some studies were high risk bias

2 Biases were not minimized in all included studies

${ }^{3}$ The $95 \% \mathrm{Cl}$ included the null value

${ }^{4}$ Randomization was not adequate in some studies

${ }^{5}$ Heterogeneity was very high

${ }^{6}$ The $95 \% \mathrm{Cl}$ included the null value

7 Other studies did not include randomization

${ }^{8}$ The $95 \% \mathrm{Cl}$ included the null value

\section{Statistical analysis}

Mean and standard deviation (SD) were used to compare the effect of interventions between two groups for continuous variables. Standard error (SE) and $95 \%$ confidence intervals were used to compute SD, if SDs were not reported in primary studies. The meta-analysis was performed, using the random fixed effect model, and data were pooled to generate a weighed MD and $95 \%$ confidence intervals $(95 \% \mathrm{Cl})$. Pvalues less than 0.05 were considered statistical significant. Clinical heterogeneity was assessed by comparing exercises programs, length of follow-up and stage of diseases. Statistical heterogeneity was computed, using $\mathrm{I}^{2}$ statistic tests. The Cochrane Handbook was used for classification of heterogeneity: low heterogeneity [0-40\%]; moderate heterogeneity [30-60\%]; substantial heterogeneity [50-90\%]; and considerable heterogeneity [75-100\%]. Subgroup analyses were conducted according to three main outcomes included in the model. As the main outcomes were not statistically significant, meta-regression analysis was performed to assess the impact of interventions on inflammatory markers. The analyses were performed by two independent reviewers, using RevMan 5.

\section{Results}

A total of 2040 reports were retrieved from our search strategies, 2002 did not meet the eligibility criteria. A total of 38 articles were assessed. From these, 8 were wrong publications, 9 did not describe the exercises programs, 5 did not include well reported outcomes, and 3 were duplicates. Twelve eligible original RCTs met the inclusion criteria. In addition, the resistance and aerobic exercises were common among the selected studies. The authors described the mode, frequency of each component of exercises regimen as recommend by ACS. Table 1 summarizes the characteristics of included studies. Eighteen studies were used in qualitative synthesis and twelve studies met inclusion criteria for meta-analysis.

\section{Quality assessment of included studies}


Random sequence was adequate with $83 \%$ of studies and $17 \%$ included high risk of bias. Allocation concealment was $25 \%$ low risk of bias, $67 \%$ high risk of bias and $8 \%$ unclear. Blinding of participants and personnel was $67 \%$ high risk of bias and $33 \%$ unclear. Blinding of outcome represented $33.33 \%$ low risk of bias, $41.67 \%$ high risk of bias and $25 \%$ unclear. Incomplete outcome data and selective reporting was $100 \%$ well controlled. Other bias was well controlled in $50 \%$ of studies, $41.67 \%$ reported unclear other bias and $8.33 \%$ was high risk of bias. Figure 2 shows the risk assessment based on PRISMA guidelines.

Subjects

The mean ages of postmenopausal BC women ranged from 49 to 56 years. Study participants presented with different stages of cancer, treatment modalities and various lengths of the follow-ups. Time since diagnosis was rarely reported by trial authors. Twelve trials included in review can be found in the reference list $15,16,24,40,41-48$. Clinical trials were not included in meta-analysis for unclear reporting, but they were reported in qualitative syntheses 49,50 .

Interventions

Seven studies assessed the effects of MSE (aerobic and resistance exercises) on mediators of inflammation $15,16,24,43,44,45,47$. One trial tested the effects of a supervised cycle ergometers program ${ }^{41}$. One other trial tested the effects of supervised aerobic exercises coupled with usual care ${ }^{40}$. Two trials assessed the effects of yoga coupled with usual care ${ }^{42,46}$, and one trial tested the effects of Tai-Tai supervised programs ${ }^{48}$. The mean length of interventions was 15 weeks, at a frequency 5 sessions per week for 60 minutes per MSE session. Many MSE programs were supervised by physiotherapists or physicians.

\section{Qualitative synthesis}

Rogers et al., (2012) conducted a RCT to assess the effects of MSE on mediators of inflammation in postmenopausal BCS with CVD risk factors. The authors noted small to medium no significant effect sizes for IL-10 and TNFa; and no positive effects on MSE were noted for IL- 6 and adiponectin ${ }^{15}$. Jones et al., (2013) confirmed that there was no significant effect of MSE on mediators of inflammation, such as IL-6, CRP, and TNF-a compared to no MSE ${ }^{16}$. The results were similarly confirmed by the following clinical trials that exercises programs did not induce a significant decrease in the main $\mathrm{BC}$ related cytokine concentrations $24,40,42-48$. In contrast, Fairey et al., (2005) found that exercises improved CRP concentration and reduced CVD related risk factors in postmenopausal BCS ${ }^{41}$.

Parma et al., (2015) assessed the effects of MSE on anthropometrics parameters and changes in IL-6, IL8, TNF-alpha, and CRP among postmenopausal BCS with CVD risk factors. Yoga-based exercise has proven to be beneficial for cancer survivors. A significant improvement was seen in decreased $\mathrm{BMI}$ and body fat $(P<0.001)$. However, Yoga-based exercise did not improve cardiorespiratory capacity or serum inflammatory markers. A larger study was recommended to determine if there are significant changes in mediators of inflammation as a result of participating in MSE programs ${ }^{49}$. Simonavice et al., (2014) 
found that exercises improved mediators of inflammation and muscular strength in postmenopausal BCS ${ }^{50}$. A larger prospective study was recommended to report a significant true effect size on the effects of MSE on BMD, body composition, obesity, and mediators of inflammation as predictors of drug nonresponse in cancer survivors ${ }^{50}$.

\section{Meta-analysis}

Subgroup analyses of MSE programs following three selected mediators of inflammation associated with $\mathrm{BC}$ and $\mathrm{CVD}$ are summarized and discussed in the appropriate sections below.

IL- 6. Data analyzed from 11 trials considered IL-6 as important marker associated with poor outcomes among postmenopausal BCS with other comorbidities such as CVD 15, 16, 24, 40,42, 43, 44, 45, 46, 47, 48 . Subgroup analysis showed that there was significant difference between MSE groups and control groups in reducing IL-6 concentration (MD: $0.02 ; 95 \% \mathrm{Cl}$ - 0.05 to 0.09, $\mathrm{P}=0.58$; heterogeneity: $\mathrm{Tau}^{2}=0.00$; $\mathrm{Chi}^{2}$ $\left.=4.52, \mathrm{df}=9, \mathrm{P}<0.087, \mathrm{I}^{2}=0 \%\right)$.

CRP. Five trials were considered for subgroup analysis with CRP level as an important outcome to be considered in postmenopausal BCS survivors associated with CVD risk factors $16,41,42,47,48$. The pooled effects showed that MSE was not more effective than no MSE in reducing CRP concentration among postmenopausal BCS with CVD risk factors (MD: 1.97; $95 \% \mathrm{Cl}$ : -0.25 to $4.19, \mathrm{P}=0.08$; heterogeneity: $\left.\mathrm{Tau}^{2}=5.71 ; \mathrm{Chi}^{2}=91.94, \mathrm{df}=4, \mathrm{P}<0.00001, \mathrm{I}^{2}=960 \%\right)$.

TNF-alpha: Seven trials were considered for subgroup analysis $15,16,42,43,44,47,48$. The pooled effects showed that MSE was not more effective than no MSE in reducing TNF-alpha concentration among postmenopausal BCS with CVD risk factors (MD: $0.54 ; 95 \% \mathrm{Cl}$ : 0.45 to $1.53, \mathrm{P}=0.13$; heterogeneity: $\left.\mathrm{Tau}^{2}=0.23 ; \mathrm{Chi}^{2}=4.28, \mathrm{df}=4, \mathrm{P}<0.28, \mathrm{I}^{2}=0 \%\right)$.

\section{Meta-regression}

There was moderate evidence that MSE decreased the MD of inflammatory markers in breast cancer patients with CVD risk factors (MD: 0.31; $95 \%$ Cl: 0.05 to 0.57, $\mathrm{P}=0.02$; heterogeneity: Tau $^{2}=0.12$; Chi $^{2}=$ $\left.106.30, \mathrm{df}=19, \mathrm{P}<0.13, \mathrm{I}^{2}=0.50 .4 \%\right)$. These results confirm the hypothesis that $\mathrm{BC}$ 's long latency and multifactorial etiologies made evaluation of these biomarkers a challenge. Many shared risk factors should be considered while treating postmenopausal BCS. Obesity is a growing public health challenge associated with NCDs, immune modulation and HRT effects on cardiovascular should be taken in account. The effects of the exercises on markers of inflammation should be evaluated using medical, biomedical, and familial risk factors for personalized therapy among these patients. Figure 2 shows the forest plots of pooled results of subgroup analyses and meta-regression for three mediators of inflammation (IL-6, CRP, TN-alpha). 


\section{Discussion}

This meta-regression summarizes the best available evidence regarding the effects of MSE on mediators of inflammation, anthropometric data, and further perspective for interventions to improve treatment outcomes among BCS survivors at risk for metabolic diseases, such as CVD. The pooled evidence from RCTs conducted to assess the effects of exercise programs on mediators of inflammation in postmenopausal BCS susceptible to metabolic syndrome, such as CVD, showed moderate level of evidence to recommend less than three inflammatory markers (IL-6, CRP and TNF-alpha) for evidencebased personalized therapy. In light of the present evidence, clinical, chemical, and genetic factors should be incorporated in therapeutic models. A comprehensive literature search highlighted the research gaps with regards to the effect of MSE programs on anthropometric predictors and associated mediators of inflammation in postmenopausal BCS likely exposed to a number of treatment-induced adverse events. A number of studies identified that lifestyle interventions are the adjuvant therapies in improvement of body composition, including HRQOL, reduction in BMI, and decreased body fat $41,49,50,51$. Changes in insulinlike growth factor I (IGF-I) were also identified to play a role in pathogenesis of both cancer and metabolic syndrome, such as diabetes ${ }^{51}$. The association between obesity and inflammation, and between chronic conditions and cancer subtypes, was described in literature based on known biological pathways. Changes in the adipose tissue, modulated by gene-environment interactions, in the cases of cancer and metabolic diseases such as CVD, modulation of adipocyte levels, hypoxia, drugs interactions, and oxidase stress, might lead to a chronic state of inflammation in predisposed patients such as postmenopausal BCS with additional comorbidities. The increased risk of obesity-related cancers could be mediated, in part, by these changes in the adipose tissues ${ }^{52}$.

Elevated CRP is associated with increased response to proinflammatory cytokines (IL-6, TNF-alpha) following immune response, infection or inflammation. CRP concentration has been shown to increase with elevated BMI, smoking status, and HRT in post-menopausal women. CRP can be decreased with physical activities, healthy diet, and higher alcohol intake ${ }^{53,54}$. Although reverse causality induced by acute inflammatory process in oncogenic patients could be over- or under-estimated in this review, based on study heterogeneities included in meta-analysis, new studies with rigorous methodologies and larger sample sizes may change our actually level of evidence. Additionally, a body of knowledge on the safety and effectiveness of exercise programs in improving general quality of life in cancer survivors are available in literature $14,18,34-37,55,56$. Most of these studies were able to provide the level of evidence on the efficacy and effectiveness of MSE in reducing treatment related adverse events and the effects of exercise programs on serum cytokines changes in postmenopausal BCS. Zaidi et al., (2018) discussed the chronicity of the disease and it produces long-term physiological and psychological manifestations, which adversely affect the quality of life of BCS and the options for personalized exercise programs to mitigate the potential side effects ${ }^{57}$. The implementation of these strategies is different in continents, such as Africa, which still have a health systems challenge. The committee highlighted the needs for addressing gaps in knowledge on screening, monitoring, prevention, and management of various cardiovascular toxicities among BCS with $\mathrm{CVD}^{58}$. These limitations were due to lack of enough clinical 
trials and the meta-analyses and novel studies are warranted on this topic. A review investigating the effects of exercise interventions on CVD risk factors during and after completion of BC treatment suggested that MSE may be an effective strategy to control treatment-associated CVD effects in BCS and more studies are needed to define the effects of exercises on CVD and cancer outcomes ${ }^{59}$. Further, a review by Lucius and Trukova (2015) on assessment of lifestyle interventions, including nutrition and exercises, on cardiotoxicity and predictors of treatment failure in postmenopausal BCS with CVD was conducted. The authors identified that weight management is a key adjuvant therapy for these patients. This is because many postmenopausal women had already exhibited CVD risk factors at diagnosis of BC 60 . Although obesity is a consistent risk factor for CVD, other risk factors are not yet studied in literature, such as diabetes and hypertension, and contributions of genetic risk factors need further assessment toward lifestyle interventions.

\section{Limitations}

Nowadays, few studies have examined the effects of exercises on inflammatory markers in BCS with CVD risk factors. Also, most of these studies have minimal sample sizes and low power; by the way, the evidence level is not quantified by levels of Evidence and Grades of Recommendations because of lack of meta-analyses (Unclear). It is difficult to evaluate whether the type of exercises and dose of exercise may influence the mediators of inflammation similarly or differently. Current level of evidence is inconclusive whether BCS with CVD risk factors have similar exercise-induced inflammatory responses compared with healthy individuals towards are also on targeted drugs. In addition, lack of objective tools, such as accelerometers, to measure exercise regimens and examine the effects of exercises on disease outcome for the patients participating in community based programs were not mentioned in many studies. Result discrepancies identified through different reviews may be due to the wide range of disease stages, as well as, the various treatment options recommended for BCS. Moreover, exercise modalities have been very diverse, with studies ranging from resistance, aerobic, mixed doses, and even non-conventional exercise interventions, such as Tai-Chi. Further, exercise modes, intensities, and follow-up periods differ from study to study, all resulting in no generalizability of findings for cytokines response. Another limitation is that some studies could not be included in the meta-analysis because of lack of sufficient RCTs.

Even though cytokines (CRP, IL- 6 and TNF-alpha) seem to have a better concentration over time, misclassification is likely because only one measurement of CRP or IL- 6 was assessed at study baseline and endpoint. Furthermore, only three markers were considered in this review. Additional inflammatory markers were reported in other reviews to be associated with different metabolic syndrome, such IGFBP-3. Other subclasses of proinflammatory cytokines, monocyte chemoattractant protein 1 (MCP-1), CD40 ligand and lipoprotein-associated phospholipase were not assessed in this study. Thus, dose-response meta-analysis assessing the effects of different lifestyle interventions on phenotypes and genotypes of inflammatory profiles in postmenopausal BCS could be needed in different population subgroups. This could provide evidence-based generalized recommendations. Lastly, many countries, especially those of Africa, and races were not represented in light of the present findings. 


\section{Further perspective}

Obesity and weight gain have been identified as the most important risk factors for development and progression of postmenopausal $B C{ }^{61,62}$. Als reduce the production of estrogen, decreasing stimulation of hormone receptor-positive $\mathrm{BC}{ }^{20}$. Als may be less effective in obese women, due to the greater quantity of aromatase in peripheral fatty tissue. A review conducted by loannides et al., (2017) supported the evidence of a negative effect of obesity on Al efficacy in postmenopausal hormone receptor-positive BCS 63 . The metabolic syndrome characterized by central obesity, glucose intolerance, hypertension and dyslipidaemia, is a common feature linked to inflammation in cancer subtypes also reported among BCS on Als. This may raise some concerns especially in the adjuvant setting where the aim of treatment is to cure, and for postmenopausal patients who are already at risk for CVD. As discussed early on, the effects of endocrine therapy, such as Als, interfere with BC and obesity related biological pathways ${ }^{4}$. Other comorbidities, such as diabetics and CVD, are indirectly induced by gene-environmental risk factors and interactions of drugs used to manage these complex diseases. Overweight and obesity, as well as, postmenopausal status are well-known risk factors for CVD ${ }^{4}$. A meta-analysis by Saadat et al., (2012) suggested that the apolipoprotein E (APOE) gene allele is a low-penetrant risk factor for development of $B C{ }^{64}$. One study revealed that $B C$ patients with the APOE4 allele have low plasma triglyceride levels when receiving tamoxifen therapy ${ }^{65}$. The authors concluded that tamoxifen therapy increases serum triglyceride levels and may induce severe hypertriglyceridemia in BCS. A study examining the change in lipid profile produced in response to TAM therapy established the relationship between ApoE genotype and menopausal state in BCS. The final analysis showed that TAM treatment induced similar plasma triglyceride increases in patients with positive or negative APOE genotype. Compared to premenopausal patients, postmenopausal BC patients demonstrated a more beneficial lipid profile change in response to treatment ${ }^{66}$.

ApoE genes involved in lipoprotein synthesis and metabolism are considered as promoters of chronic heart diseases ${ }^{67}$. ApoE gene is part of a broader paradigm in clinical research, highlighted to play a role in gene-environmental risk factors interactions, as a predictor for common metabolic diseases such as $C V D$, via unifying obesity related intermediate phenotype, Alzheimer's disease (AD), dementia, atherosclerosis, multiple sclerosis, peripheral artery diseases, diabetes, stroke, and cancer subtypes, as recently reported in molecular epidemiology of $\mathrm{BC}{ }^{67}$. ApoE is a normal small molecule composed of very low-density lipoproteins (LDL) and high-density lipoproteins (HDL), and is involved in various metabolic functions. These include lipoproteins metabolisms, cholesterols transport, tissue repair, immune response and regulation, as well as cell growth and differentiation. The localization, frequencies and biological pathways in both CVD and cancer patients have been studied elsewhere in terms of CVD, neurological dysfunction, neuromuscular diseases and different types of diabetes ${ }^{67,68}$. However, while many studies have tried to examine the role of the ApoE gene as molecular intermediate risk predictor for a number of conditions in multi-ethnic populations, few authors have evaluated its contribution in BC patients associated CVD ${ }^{65,66}$. Only one study evaluated the association between ApoE gene and the risk of BC in 
both non-Hispanic white and African-American women ${ }^{65}$. The evidence is not sufficient to recommend its utility for personalized medicine. Additionally, APOE $\varepsilon-4$ status has been associated with greater cortical amyloid deposition, whereas exercise has been associated with less in cognitively normal adults ${ }^{69}$. Head et al., (2012) examined whether physical activity moderates the association between ApoE gene and amyloid deposition in cognitively normal subjects. The authors identified a significant interaction between ApoE gene and exercises $(p=0.008)$, such that a more sedentary lifestyle was significantly associated with higher PIB binding for $\varepsilon-4$ carriers $(p=0.013)$ but not for $\varepsilon-4$ non-carriers $(p=0.208)$. All findings remained significant after controlling for age, gender, education, hypertension, BMI, diabetes, heart problems, history of depression and interval between assessments ${ }^{69}$. A study conducted by Lückhoff et al., (2015) to compare the genotype distribution and allele frequencies of APOE $\varepsilon-2$ (rs7412) and $\varepsilon-4$ (rs429358) in 537 South Africans participating in a chronic disease screening algorithm with the goal to establish the causal pathways between $A D$ related familial predisposition and dyslipidemia. The authors identified a statistically significant differences in the genotype distribution for APOE $\varepsilon-2$ ( $p=$ $0.034)$, as well as, APOE $\varepsilon-4(p=0.038)$ in patients with the family history of $A D{ }^{68}$. In addition, $L D L$ cholesterol levels were inversely associated with physical activity among the study participants with familial history of $A D(p<0.001)$, but the association was not found in patients without family history of $A D(p=0.257)$. Moreover, these results may lead to the application of personalized medicine in patients clinically diagnosed with familial hypocholesteremia to exclude APOE gene as an important determinant of CVD risk factors. The authors concluded that APOE genotyping, as risk prediction for dyslipidemia in the South African population, should derive the greatest benefit from early lifestyle-based interventions intended to decrease CVD recurrence in AD susceptible patients ${ }^{68}$. Also, its incorporation in diagnosis of postmenopausal BCS with CVD risk factors may play a role in preventing cancer drug-related adverse events and may positively impact on HRQOL of the patients. Although many studies have tried to assess the effects of MSE on obesity-induced side effects in BCS, to date, the evidence is lacking on the effects of current lifestyle interventions on ApoE in postmenopausal BC survivors with additional comorbidities, such as CVD and diabetes.

\section{Conclusion}

There is a moderate level of evidence on the effects of MSE on mediators of inflammation in postmenopausal BCS. Robust prospective studies are warranted to assess the impact of MSE and dietary interventions on various mediators of inflammation, based on BC subtypes, exercise dose-responses and associated comorbidities. Multidisciplinary approaches, including lifestyle interventions, clinical assessment, and biomedical technologies and geno-phenotype correlations should be considered in routine management of postmenopausal BCS to reduce potential obesity-related co-morbidities. Future studies should be conducted to establish the association between hs-CRP and obesity in postmenopausal with CVD risk factors and the impact of the shared risk factors on BCS outcomes.

\section{Abbreviations}


APOE Apolipoprotein E

Als Aromatase inhibitors

BMl: Body mass index

BC Breast cancer

BCS Breast cancer survivors

CRP C-reactive protein

IL-6 Interleukin-6

MSE Medically supervised exercise

RCT Randomized controlled trial

TNF-a Tumor necrosis factor alpha

\section{Declarations}

- $\quad$ Ethics approval and consent to participate: N/A

- $\quad$ Consent to publish: All authors read the manuscript and approved for the submission

- $\quad$ Availability of data and materials: N/A

- $\quad$ Competing interests: no conflict of interest declared

- $\quad$ Funding: There is no funding available to conduct this review. However, the primary author is the beneficiary of National Research Foundation bursary allocated for PhD program in Stellenbosch University.

\section{Authors' Contributions:}

1. JPM Milambo assisted in designing, search strategy, registering of review, data extraction, and risk of bias assessment, data analysis, management and writing of manuscript.

2. MJ Kotze assisted in designing and development of a conceptual framework, Critical appraisal and quality improvement;

3. RT Erasmus reviewed and assessed the risk of bias of the manuscript, administration and critical appraisal;

4. JM Akudugu contributed in project management, edition, critical appraisal, supervision, data management and extraction;

5. LJ Tamuzi assisted in data analysis, extraction and risk of bias assessment,

\section{Acknowledgments}

Page 18/28 
$\operatorname{Dr}$ A. Bulabula assisted in generating comprehensive search strategies. He acted as independent reviewer, and assisted in performing risk of bias assessment and data analysis of the present work

\section{References}

1. Ferlay J, Soerjomataram I, Dikshit R, et al., (2015) 'Cancer incidence and mortality worldwide: Sources, methods and major patterns in GLOBOCAN 2012', J. Cancer, 136(5): E359-E386.

2. Miller KD, Siegel RL, Lin CC, et al., (2016). Cancer treatment and survivorship statistics, 2014. CA Cancer J Clin. ; 016; 66:271-289

3. Koene RJ, Prizment AE, Blaes A, et al., (2016). Shared Risk Factors in Cardiovascular Disease and Cancer. Circulation; 133(11):1104-14.

4. Bardia A, Arieas ET, Zhang Z A, et al.,(2012). Comparison of breast cancer recurrence risk and cardiovascular disease incidence risk among postmenopausal women with breast cancer; Breast Cancer Res Treat; 131(3): 907-914.

5. King MC, Marks JH, Mandell JB, et al. (2003) 'Breast and ovarian cancer risks due to inherited mutations in BRCA1 and BRCA2', Science, 302(5645): 643-646.

6. Schiavon G and Smith IE, (2014). Status of adjuvant endocrine therapy for breast cancer. Breast Cancer Res; 16(2): 206

7. Park NJ, Chang Y, Bender C, et al., (2017). Cardiovascular disease and mortality after breast cancer in postmenopausal women: Results from the Women's Health Initiative. PLoS One 12(9): e0184174.

8. Patnaik JL, Byers T, DiGuiseppi C, et al., (2011). Cardiovascular disease competes with breast cancer as the leading cause of death for older females diagnosed with breast cancer: a retrospective cohort study. Breast Cancer Res; 13:R64.

9. Gulati M and Mulvagh SL, (2018). The connection between the breast and heart in a woman: Breast cancer and cardiovascular disease. Clin Cardiol 41(2):253-257 ;

10. Levis BE, Binkley PF, Shapiro CL, et al., (2017). Cardiotoxic effects of anthracycline-based therapy: what is the evidence and what are the potential harms? Lancet Oncol.;18(8):e445-e456.

11. Lønning PE, Haynes BP, Dowsett M, et al. (2014) 'Relationship of body mass index with aromatisation and plasma and tissue oestrogen levels in postmenopausal breast cancer patients treated with aromatase inhibitors.', Eur J Cancer, 50(6): 1055-1064.

12. Picon-Ruiz M, Morata-Tarifa C, Valle-Goffin JJ, et al. (2017). 'Obesity and adverse breast cancer risk and outcome: Mechanistic insights and strategies for intervention.' CA Cancer J Clin, 67(5): 378397.

13. Passos CS, Ribeiro RS, Rosa TS, et al.,(2017). Obesity, inflammation, physical inactivity and risk for cancer. J Med Oncl Ther; 2 issue 1;2(1):16-19.

14. De Jesus Leite MAF, Puga GM, Arantes FJ, et al., (2017). Effects of combined and resistance training on the inflammatory profile in breast cancer survivors: A systematic review. Complement Ther Med. 36:73-81 
15. Rogers LQ, Fogleman A, Trammell R, et al.,(2012). Effects of a Physical Activity Behaviour Change Intervention on Inflammation and Related Health Outcomes in Breast Cancer Survivors: Pilot Randomized Trial. Integr Cancer Ther 12(4) 323-335

16. Jones SB, Thomas GA, Hesselsweet SD, et al.,(2013). Effect of Exercise on Markers of Inflammation in Breast Cancer Survivors: The Yale Exercise and Survivorship Study. Cancer Prev Res (Phila). 6(2): 10.1158/1940-6207.CAPR-12-0278.

17. Khan S, Shukla S, Sinha S et al. (2013) 'Role of adipokines and cytokines in obesity-associated breast cancer: Therapeutic targets', Cytokine Growth Factor Rev, 24(6): 503-513.

18. Mills, RC (2017). Breast Cancer Survivors, Common Markers of Inflammation, and Exercise: A Narrative Review. Breast Cancer (Auckl); 11: 1178223417743976.

19. Thomson CA, Thompson PA, Wright-Bea J et al., (2009). A Metabolic syndrome and elevated Creactive protein in breast cancer survivors on adjuvant hormone therapy. $J$ Womens Health; 18(12):2041-7.

20. Pfeiler G, Königsberg R, Hadji P, et al., (2013) 'Impact of body mass index on estradiol depletion by aromatase inhibitors in postmenopausal women with early breast cancer'. Br J Cancer, 109(6): $1522-1527$.

21. Huiart L, Ferdynus C, Giorgi R, (2013) 'A meta-regression analysis of the available data on adherence to adjuvant hormonal therapy in breast cancer: Summarizing the data for clinicians', Breast Cancer Res Treat, 138: 325-328.

22. Doyle C, Kushi LH, Byers T, et al., (2013). Nutrition and physical activity during and after cancer treatment: an American Cancer Society guide for informed choices. CA: a Cancer Journal for Clinicians; 56(6):323-53.

23. Schmitz KH, Courneya KS, Matthews C, et al.,(2010). American College of Sports Medicine roundtable on exercise guidelines for cancer survivors. Med Sci Sports Exerc.; 42(7):1409-1426.

24. Van Vulpen JK, Schmidt ME, Velthuis MJ, et al., (2018). Effects of physical exercise on markers of inflammation in breast cancer patients during adjuvant chemotherapy. Breast Cancer Res Treat; 168:421-431

25. Babaei Z, Moslemi D, Parsian H, et al. (2015) 'Relationship of obesity with serum concentrations of leptin, CRP and IL-6 in breast cancer survivors', J Egypt Natl Canc Inst, 27(4): 223-229.

26. Dutra MT, Avelar BP, Souza VC, et al. (2017) 'Relationship between sarcopenic obesity-related phenotypes and inflammatory markers in postmenopausal women', Clin Physiol Funct Imaging., 37(2): 205-210.

27. Chan DS, Bandera EV, Greenwood DC, et al.,(2015). Circulating C-Reactive Protein and Breast Cancer Risk-Systematic Literature Review and Meta-analysis of Prospective Cohort Studies. Cancer Epidemiol Biomarkers Prev; 24(10):1439-49

28. Ollberding NJ, Kim Y, Shvetsov YB, et al.,(2013). Prediagnostic leptin, adiponectin, C-reactive protein, and the risk of postmenopausal breast cancer. Cancer Prev Res (Phila).. 6:188-195. 
29. Wang J, Lee I, Tworoger SS, et al.,(2015). Plasma C-reactive protein and risk of breast cancer in two prospective studies and a meta-analysis. Cancer Epidemiol Biomarkers Prev, 24:1199-1206.

30. Friedenreich, CM (2010).The role of physical activity in breast cancer etiology. Seminar Oncology, 37:297-302.

31. Meneses-Echávez JF, González-Jiménez E, Ramírez-Vélez R, et al. (2015) ‘Effects of supervised exercise on cancer-related fatigue in breast cancer survivors: a systematic review and meta-analysis', BMC Cancer, 15: 77.

32. Mustian KM, Sprod LK, Palesh OG, (2009). Exercise for the Management of Side Effects and Quality of Life among Cancer Survivors. Curr Sports Med Repo; 8(6): 325-330.

33. Bodai BI and Tuso P, (2015). Breast Cancer Survivorship: A Comprehensive Review of Long-Term Medical Issues and Lifestyle Recommendations. Perm Journal Spring;19(2):48-79

34. Segal R, Zwaal C, Green E, et al., (2017). Exercise for people with cancer: a systematic review, Curr Oncol;24(4):e290-e315

35. Zhu G, Zhang X, Wang Y, et al.,(2016). Effects of exercise intervention in breast cancer survivors: a meta-analysis of 33 randomized controlled trails. Onco Targets Ther;9: 2153-2168

36. Löf M, Bergström K, Weiderpass E, et al.,(2012). Physical activity and biomarkers in breast cancer survivors: a systematic review. Maturitas; 73:134-42.

37. Meneses-Echávez JF, Correa-Bautista JE, González-Jiménez E, et al. (2015). The Effect of Exercise Training on Mediators of Inflammation in Breast Cancer Survivors: A Systematic Review with Metaanalysis. Cancer Epidemiol Biomarkers Prev, 25(7); 1009-17.

38. David Moher D, Liberati A, Tetzlaff J, et al.,(2009). The PRISMA Group. Preferred Reporting Items for Systematic Reviews and Meta-Analyses: The PRISMA Statement. Public Library of Science; 6(6): e1000097. doi:10.1371/journal.pmed1000097

39. Higgins JPT, Churchill R, Chandler J, (editors),(2017) Cochrane Handbook for Systematic Reviews of Interventions Version 5.2.0 (updated February 2017), Cochrane, 2017. Available from Cochrane Community.

40. Schmidt ME, Meynköhn A, Habermann N, et al.,(2015). Resistance Exercise and Inflammation in Breast Cancer Patients Undergoing Adjuvant Radiation Therapy: Mediation Analysis From a Randomized Controlled Intervention Trial. Int J Radiat Oncol Biol Phys; Vol. 94, No. 2, pp. 329-337

41. Fairey AS, Courneya KS, Field CJ et al., (2005). Effect of exercise training on C-reactive protein in postmenopausal breast cancer survivors: A randomized controlled trial. Brain Behav Immun, 19 : $381-388$

42. Bower JE, Greendale G, Crosswell AD, et al.,(2014). Yoga reduces inflammatory signaling in fatigued breast cancer survivors: a randomized controlled trial. Psych neuroendocrinology, 43:20-9.

43. Ergun M, Eyigor S, Karaca B, et al.,(2013). Effects of exercise on angiogenesis and apoptosis-related molecules, quality of life, fatigue and depression in breast cancer patients. Eur J Cancer Care; 22:626-37. 
44. Gómez AM, Martínez C, Fiuza-Luces C, et al.,(2011). Exercise training and cytokines in breast cancer survivors. Int J Sports Med 2011; 32:461-67.

45. Hutnick NA, WilliamsNI, Kraemer WJ, et al.,(2005). Exercise and lymphocyte activation following chemotherapy for breast cancer. Med Sci Sports Exerc;37(11):1827-35.

46. Janelsins MC, Davis PG, Wideman L, et al.,(2011). Effects of Tai Chi Chuan on insulin and cytokine levels in a randomized controlled pilot study on breast cancer survivors. Clin Breast Cancer, 11 $: 161-70$.

47. Tizdast N, Ghazalian F \& Gholami $M,(2016)$. The Effect of Exercise Type on Inflammatory Markers in Obese Survivors With Breast Cancer: Randomized Control Trial. Health Scope. 01, 2016, 5 (4); e33421

48. Swisher AK, Abraham J, Bonner D, et al.,(2015). Exercise and dietary advice intervention for survivors of triple-negative breast cancer: effects on body fat, physical function, quality of life, and adipokine profile. Support Care Cancer, 10:2995-3003.

49. Parma DL, Hughes DC, Ghosh S et al.,(2015). Effects of six months of Yoga on inflammatory serum markers prognostic of recurrence risk in breast cancer survivors. Springer Plus; 4:143.

50. Simonavice E, Liu PY, llich JZ, et al.,(2014). The effects of a 6-month resistance training and dried plum consumption intervention on strength, body composition, blood markers of bone turnover, and inflammation in breast cancer survivors. Appl Physiol Nutr Metab, 39: 730-9.

51. Burgers AMG, Biermasz NR, Schoones JW et al.,(2011). Meta-Analysis and Dose-Response Metaregression: Circulating Insulin-Like Growth Factor I (IGF-I) and Mortality. J Clin Endocrinol Metab, Pages 2912-2920.

52. Maria E. Ramos-Nino, (2013) "The Role of Chronic Inflammation in Obesity-Associated Cancers," ISRN Oncology, vol. 2013, Article ID 697521, pages 25.

53. Chan, DSM, Bandera EV, Greenwood DC, et al. (2015) Circulating C-reactive protein and breast cancer risk - systematic literature review and meta-analysis of prospective cohort studies. Cancer Epidemiol Biomarkers Prev, 24 (10). 1439 - 1449.

54. Guo L, Liu S, Zhang S, et al.,(2015) Association Between C-reactive Protein and Risk of Cancer: A Meta-analysis of Prospective Cohort Studies. Asian Pac J Cancer Prev, 14 (1), 243-248

55. Kim TH, Chang JS, Kong ID, et al., (2017). Effects of Exercise Training on Physical Fitness and Biomarker Levels in Breast Cancer Survivors. J Lifestyle Med; 7(2): 55-62.

56. Guinan EM, Connolly EM \& Hussey J, et al, (2013) Exercise training in breast cancer survivors: a review of trials examining anthropometric and obesity- related biomarkers of breast cancer risk, PTR, $18: 2,79-89$

57. Zaidi S, Hussain S, Verma S, et al., (2017). Efficacy of Complementary Therapies in the Quality of Life of Breast Cancer Survivors; Front Oncol; 7: 326.

58. Mehta LS, Karol E. Watson KE, et al.,(2018). Cardiovascular Disease and Breast Cancer: Where These Entities Intersect: A Scientific Statement From the American Heart Association. Circulation. 137:0000 . 
59. Anthony F. Y and Lee W. J, (2016). Breast cancer treatment-associated cardiovascular toxicity and effects of exercise countermeasures. Cardio-Oncology 2:1

60. Lucius K and Trukova K, (2015) Integrative Therapies and Cardiovascular Disease in the Breast Cancer Population: A Review, Part 2 Integr Med (Encinitas). t; 14(5): 33-40.

61. Macciò A \& Madeddu C, (2011). Obesity, Inflammation, and Postmenopausal Breast Cancer: Therapeutic Implications. ScientificWorldJournal.;11: 2020-2036.

62. Carmichael A, (2006). Obesity as a risk factor for development and poor prognosis of breast cancer. BJOG; 113:1160-1166.

63. Ioannides SJ, Barlow PL, Elwood JM, et al.,(2017). Effect of obesity on aromatase inhibitor efficacy in postmenopausal, hormone receptor-positive breast cancer: a systematic review. Breast Cancer Res Treat:; 147(2):237-48

64. Saadat M, (2012). Apolipoprotein E (APOE) Polymorphisms and Susceptibility to Breast Cancer: A Meta-Analysis. Cancer Res Treat; 44(2): 121-126

65. Chang NW, Chen FN, Wu CT, et al.,(2009) Apolipoprotein E4 allele influences the response of plasma triglyceride levels to tamoxifen in breast cancer patients. Clin Chim Acta;401 (1-2):144-7.

66. Gaibar M, Fernández G, Romero-Lorca A, et al.,(2013). Tamoxifen therapy in breast cancer: do apolipoprotein E genotype and menopausal state affect plasma lipid changes induced by the drug? Int J Biol Markers; 28(4):e371-6

67. Xu M, Zhao J, Zhang Y, et al.(2016). Apolipoprotein E Gene Variants and Risk of Coronary Heart Disease: A Meta-Analysis. BioMed Research International. Volume 2016, Article ID 3912175, 12 pages

68. Lückhoff HK, Brand T, van Velden DP, et al.,(2015). Clinical Relevance of Apolipoprotein EGenotyping Based on a Family History of Alzheimer's disease; Metab Brain Dis. 31(1):213-24.

69. Head D, Bugg JM, Goate AM, et al.,(2012). Exercise engagement as a moderator of APOE effects on amyloid deposition. Arch Neurol; 69(5): 636-643.

\section{Figures}




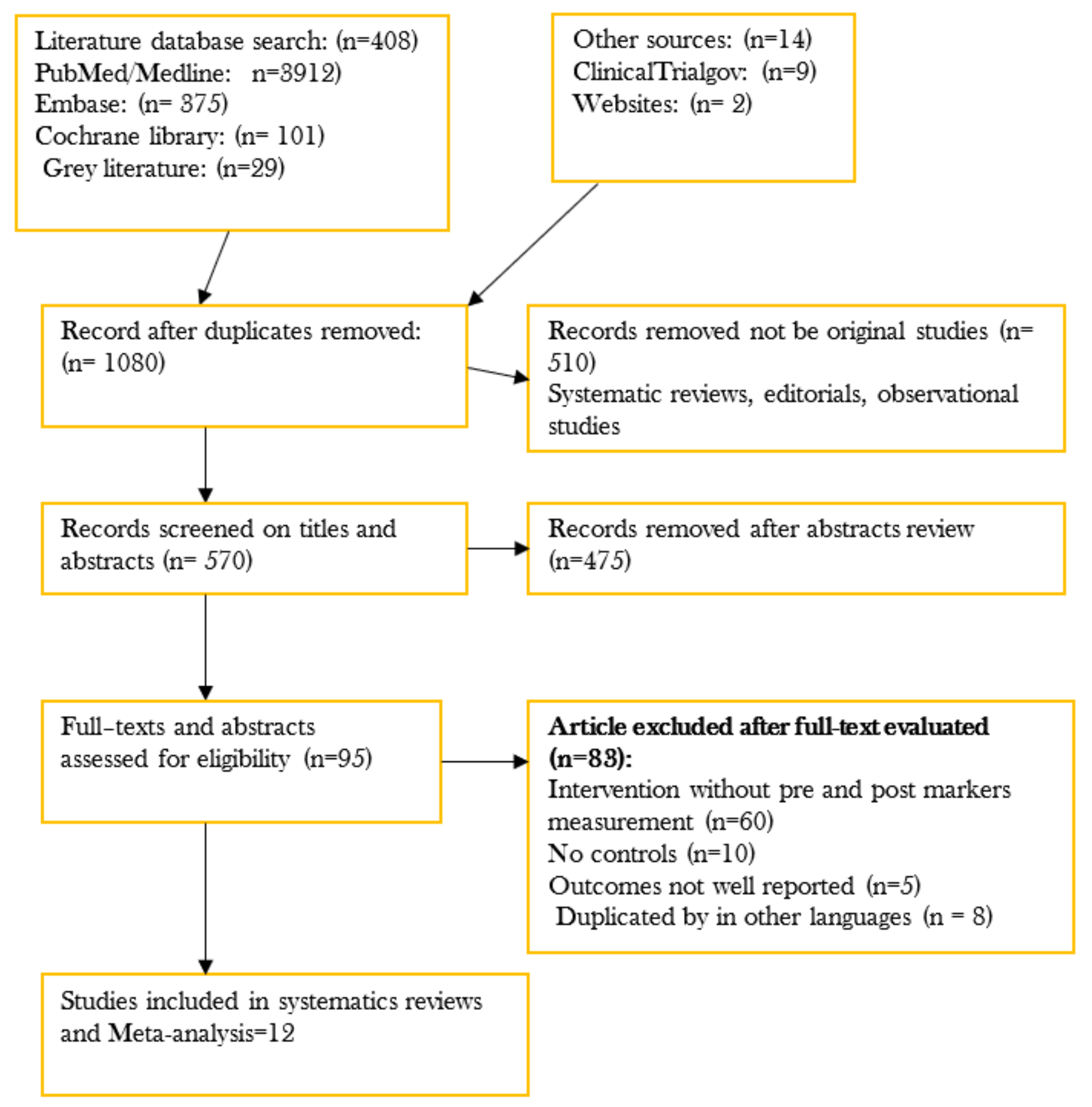

Figure 1

Flow diagram of study selection and identification 


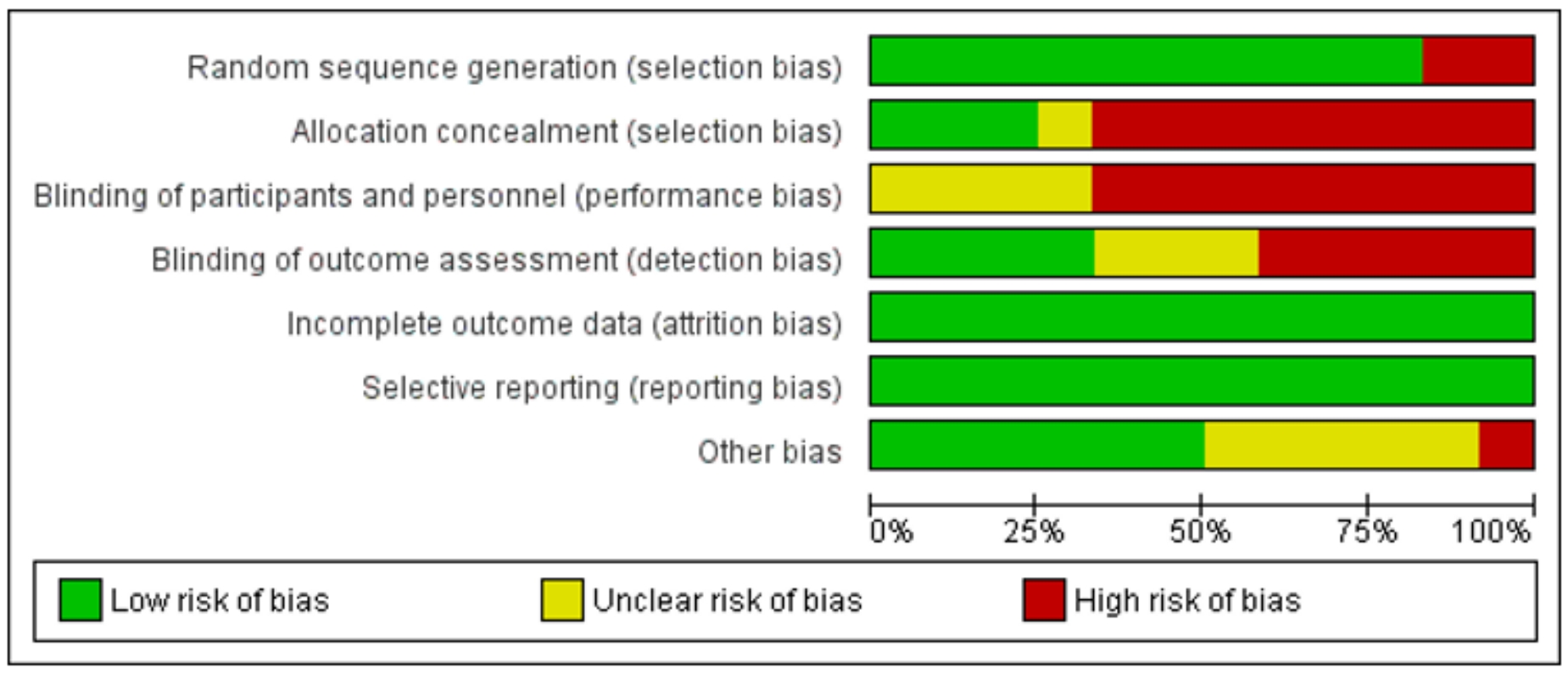

Figure 2

The risk assessment based on PRISMA guidelines. 


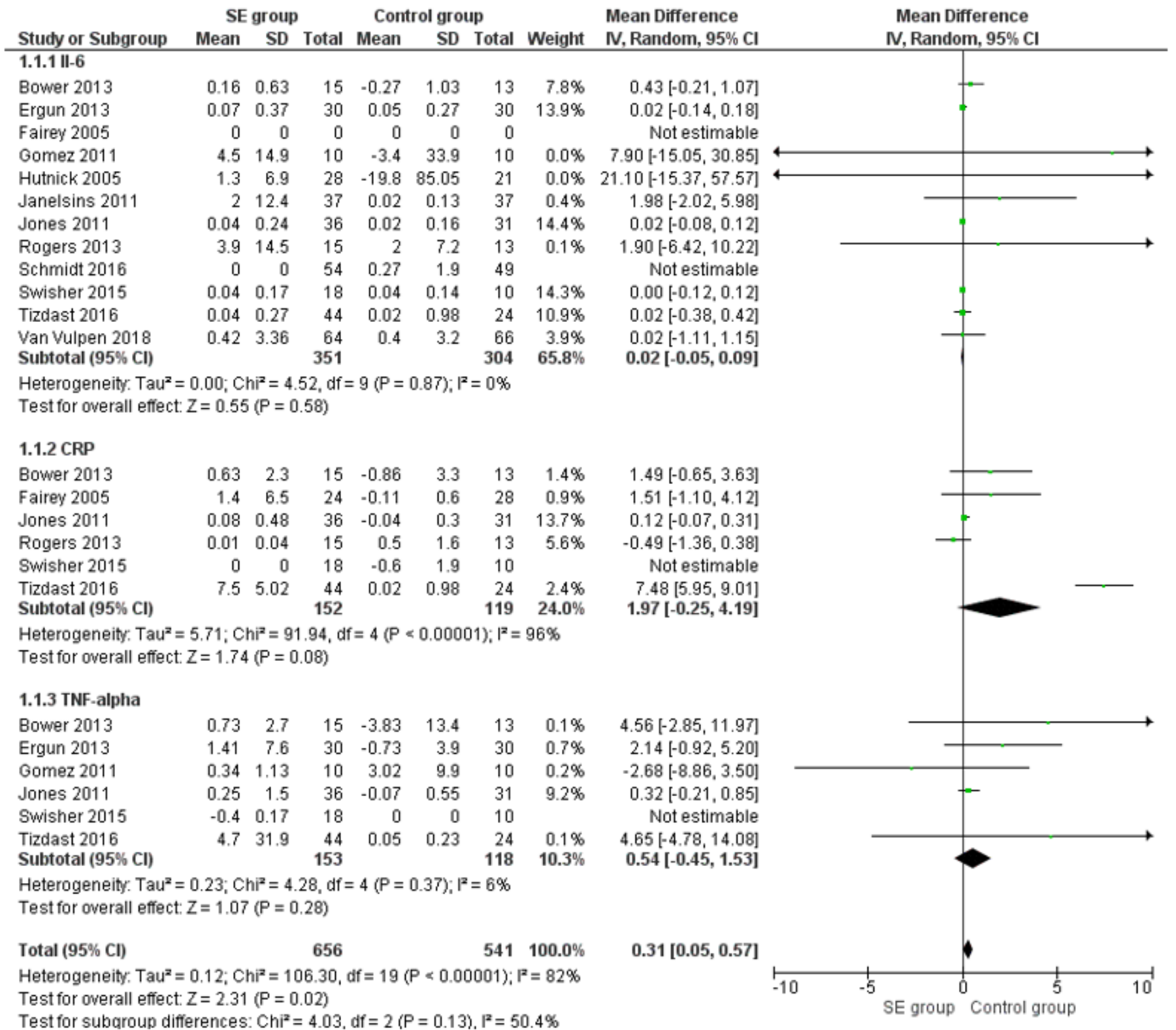

\section{Figure 3}

Forest plots of the subgroups analysis of the effects of MSE on the markers of inflammation 


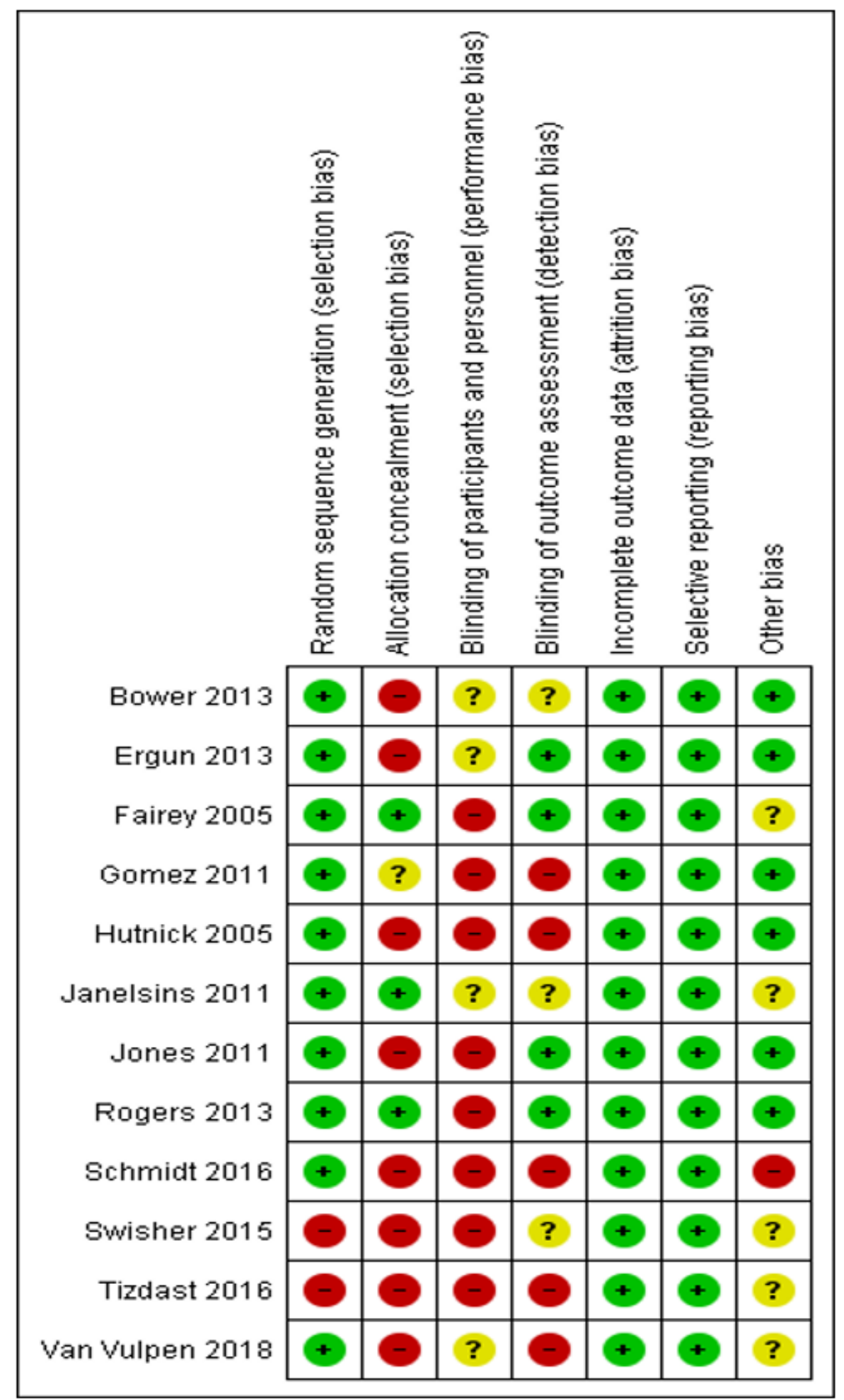

Figure 4

Risk of bias assessment

\section{Supplementary Files}

This is a list of supplementary files associated with this preprint. Click to download. 
- PRISMA2009checklist.doc 